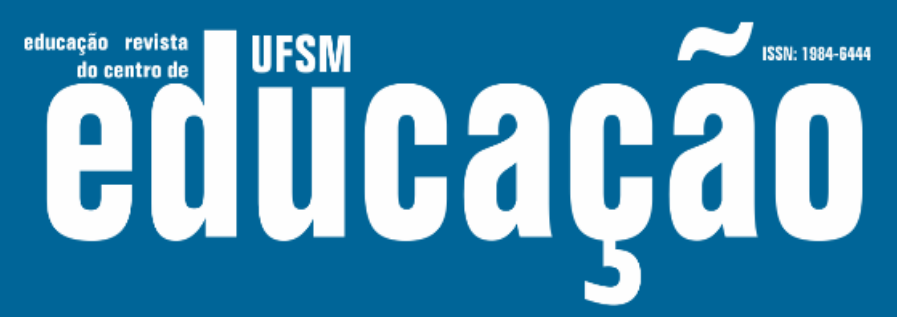

ISSN: 1984-6444 | http://dx.doi.org/10.5902/1984644435418

\title{
A educação e a experiência de si nos relatos de uma narradora às margens do Rio Doce
}

\author{
Education and the self-experience in the stories of a narrator alongside \\ Rio Doce
}

Fabiano Oliveira Moraes

Professor na Universidade Federal do Espírito Santo, Vitória, Espírito Santo, Brasil. professorfabianomoraes@gmail.com _ https://orcid.org/0000-0001-6741-4564

Monique Linciano de Azevedo Costa

Mestra pela Universidade Federal do Espírito Santo, Vitória, Espírito Santo, Brasil. moniquelincianocosta@gmail.com — https://orcid.org/0000-0002-5099-7326

Recebido em 30 de outubro de 2018

Aprovado em 12 de novembro de 2019

Publicado em 17 de dezembro de 2019

\section{RESUMO}

Objetiva compreender as práticas educacionais efetivadas por meio da propagação dos relatos orais de narradores tradicionais e as relações entre as narrativas tradicionais, as experiências de si e a educação, refletindo sobre os enredamentos entre as narrativas orais e a constituição dos sujeitos. Para tanto, faz uso dos conceitos de narrador e experiência de Benjamin (1979) e de dispositivo pedagógico, experiência e consciência de si de Larrosa (1994; 2004). Com abordagem qualitativa, trata-se, quanto aos procedimentos metodológicos, de um estudo de caso que toma por corpus as narrativas, coletadas por meio de entrevista gravada, de Geni de Oliveira Ramos, narradora tradicional da vila de Povoação (Linhares-ES), localizada na margem norte da foz do Rio Doce. A partir da transcrição da entrevista (DELGADO, 2006; MARCUSCHI, 2007), a análise de dados aponta eventuais relações dos relatos coletados com os mitos brasileiros (CASCUDO, 1983; 1998). O estudo analisa as narrativas à luz do referencial teórico, destacando trechos diretamente relacionados aos elementos da tradição e à experiência de si no âmbito da instituição de dispositivos pedagógicos e práticas educacionais no tempo e espaço da narração. Salienta, por fim, a relevância da pesquisa no registro da memória da comunidade para seu processo de re-existência diante da situação atual do Rio Doce, apontando para possíveis ações de transmissão da experiência de si das narrativas de Dona Geni às novas gerações.

Palavras-chave: Educação; Narrador; Experiência. 


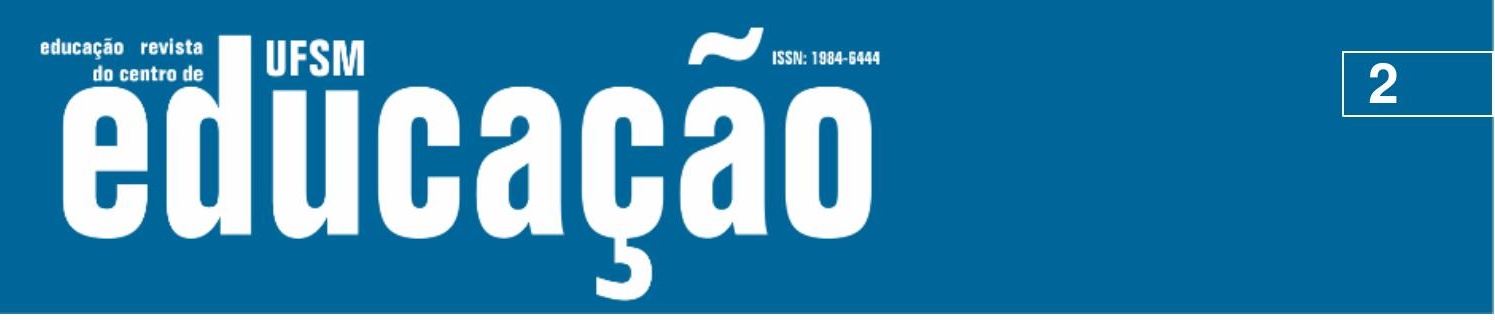

ISSN: 1984-6444 | http://dx.doi.org/10.5902/1984644435418

\section{ABSTRACT}

It aims to understand the educational practices performed through the propagation of oral narratives of traditional narrators and the relationships between traditional narratives, self-experiences and education, reflecting on the entanglements between oral narratives and the constitution of the subjects. To do so, it uses the concepts of narrator and experience of Benjamin (1979) and of pedagogic device, experience and self-awareness of Larrosa $(1994,2004)$. With a qualitative approach, according to the methodological procedures, a case study that takes as a corpus the narratives, collected by recorded interview from Geni de Oliveira Ramos, a traditional narrator from the village of Povoação (Linhares-ES), located on the north bank of the Rio Doce mouth. From the transcription of the interview (DELGADO, 2006; MARCUSCHI, 2007), the data analyses points out eventual relationships of the collected stories with the Brazilian myths (CASCUDO, 1983; 1998). This study analyzes the narratives in the light of the theoretical reference, highlighting sections directly related to the elements of tradition and to the self-experience within the scope of the institution of pedagogic devices and educational practices in the time and space of the narration. Finally, it highlights the relevance of the research in the record of the community's memory for its process of re-existence in face of the current situation of the Rio Doce, pointing to possible actions of transmission of selfexperience from Dona Geni's narratives to the new generations.

Keywords: Education; Narrator; Experience.

\section{Introdução}

O presente artigo é resultado de uma sequência de viagens para entrevistas e coletas de narrativas realizadas no litoral do estado do Espírito Santo em 2002 pelo seu coautor, e do posterior estudo de caso, tomando por corpus as narrativas de uma das narradoras tradicionais entrevistadas, realizado pela sua coautora (sob a orientação do coautor) nos anos de 2015 e $2016^{1}$.

A pesquisa teve por objetivo contribuir com os estudos que buscam entender as práticas educacionais efetivadas por meio da propagação dos relatos orais de narradores tradicionais, favorecendo desse modo a compreensão das relações entre as narrativas tradicionais, as experiências de si, a educação e a reflexão sobre as relações entre as narrativas orais e a constituição dos sujeitos. Também objetivou efetivar transcrições das narrativas do sujeito pesquisado, destacando as eventuais 


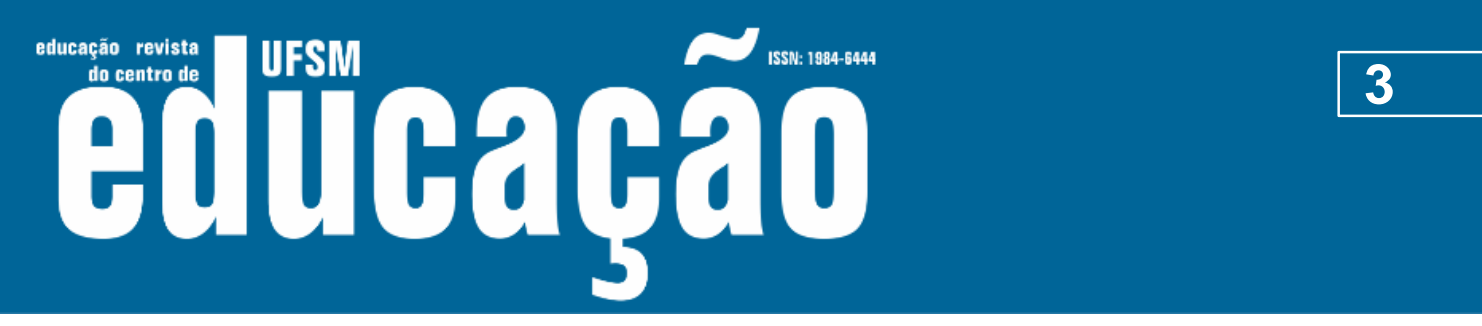

ISSN: 1984-6444 | http://dx.doi.org/10.5902/1984644435418

relações de suas narrativas com os mitos brasileiros a partir de Cascudo (1983; 1998) e analisando-as à luz dos autores tomados como referencial teórico da pesquisa.

Se considerarmos o ato de contar histórias como algo inerente às sociedades há dezenas de milhares de anos, podemos dizer que as mudanças sofridas por tal prática na sociedade ocidental nos últimos quinhentos anos, e de forma ainda mais intensa no último século, correspondem a uma transformação brusca e recente na capacidade do homem de transmitir as suas tradições às novas gerações.

[...] a arte de narrar caminha para o fim. Torna-se cada vez mais raro o encontro com pessoas que sabem narrar alguma coisa direito. É cada vez mais frequente espalhar-se em volta o embaraço quando se anuncia 0 desejo de ouvir uma história. É como se uma faculdade, que nos parecia inalienável, a mais garantida entre todas as coisas seguras, nos fosse retirada. Ou seja: a de trocar experiências (BENJAMIN, 1979, p. 57).

Para Benjamin (1979), a narrativa é colhida pelo narrador na experiência, seja ela própria ou relatada, e ao ser narrada é transformada outra vez em experiência daqueles que ouvem sua narrativa.

Larrosa (2004), por sua vez, destaca, a partir de Benjamin, que a experiência não é aquilo que passa, que acontece ou que toca, mas sim aquilo que nos passa, que nos acontece, que nos toca. No entanto, embora tantas coisas se passem em nossos dias, a experiência tem se tornado cada vez mais rara pelo excesso de informação e de opinião (que diferem da experiência), pela falta de tempo e pelo excesso de trabalho.

Essa mesma falta de tempo, somada ao excesso de trabalho, de informação e de opinião, destacada por Larrosa (2004), é reflexo da modernidade, período em que aconselhamento, sabedoria, experiência e narrador perdem espaço.

O narrador é um homem que dá conselhos ao ouvinte. Mas se hoje "dar
conselhos" começa a soar nos ouvidos como algo fora de moda, a culpa é
da circunstância de estar diminuindo a imediatez da experiência. Por causa
disso não sabemos dar conselhos nem a nós, nem aos outros. O conselho é
de fato menos resposta a uma pergunta do que uma proposta que diz
respeito à continuidade de uma história que se desenvolve agora. Para
recebê-lo seria necessário, primeiro de tudo, saber narrá-la. (Sem levar em
conta que uma pessoa só se abre a um conselho na medida em que
verbaliza a sua situação.) O conselho entretecido na matéria da vida vivida,
é sabedoria. A arte de narrar tende para o fim porque o lado épico da
verdade, a sabedoria, está agonizando. Mas este é um processo que vem
de longe. Nada seria mais tolo do que querer vislumbrar nele apenas um 


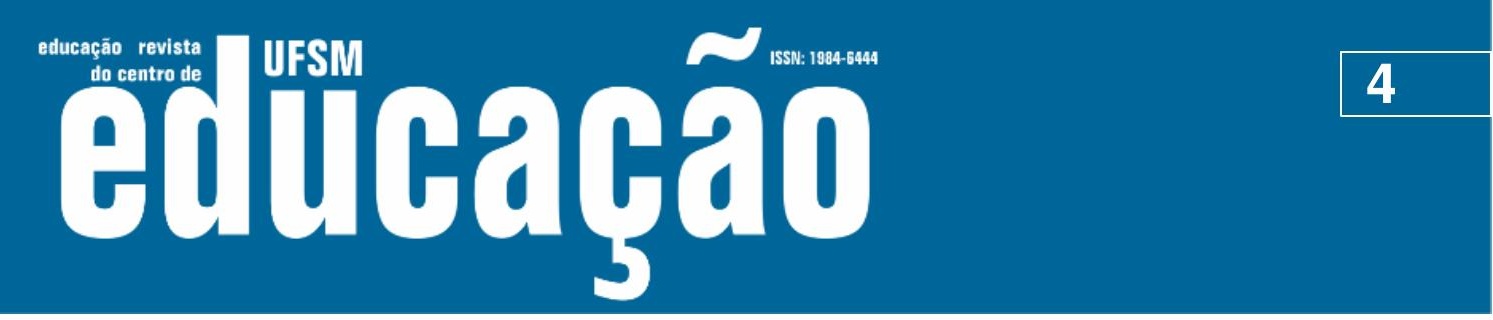

ISSN: 1984-6444 | http://dx.doi.org/10.5902/1984644435418

"fenômeno da decadência" - muito menos ainda "moderno". Ele é antes uma manifestação secundária de forças produtivas históricas seculares que aos poucos afastou a narrativa do âmbito do discurso vivo, ao mesmo tempo em que tornava palpável uma nova beleza naquilo que desaparecia (BENJAMIN, 1979, p. 59)

Larrosa (2004) afirma ainda que, como decorrência desse processo, em nosso tempo tornou-se rara a experiência de paciência, de atenção e de paixão ativa de sujeitos que estejam abertos à própria transformação como condição de renascimento.

\begin{abstract}
A experiência, a possibilidade de que algo nos passe, nos aconteça, nos toque, requer um gesto de interrupção, um gesto que é quase impossível nos tempos que correm: requer parar para pensar, para olhar, parar para escutar, pensar mais devagar, olhar mais devagar e escutar mais devagar; parar para sentir, sentir mais devagar, demorar-se mais nos detalhes, suspender a opinião, suspender o juízo, suspender a vontade, suspender o automatismo da ação, cultivar a atenção e a delicadeza, abrir os olhos e os ouvidos, falar sobre o que nos acontece, aprender a lentidão, escutar os outros, cultivar a arte do encontro, calar muito, ter paciência e dar-se tempo e espaço (LARROSA, 2004, p. 160).
\end{abstract}

Ao nos depararmos com a narração da Geni de Oliveira Ramos² (doravante, Dona Geni), que apresenta claramente essas características raras de atenção, delicadeza, lentidão, escuta, silêncio, encontro, paciência e arte de dar-se tempo e espaço, gravada na vila de Povoação, à margem norte da foz do Rio Doce, percebemos de pronto que estávamos diante de uma produção de potência educacional e cultural inestimável. Por essa razão, entre os tantos contadores que pudemos entrevistar em diversas comunidades do litoral capixaba no ano de 2002, optamos por evidenciar, no presente artigo, a importância da transmissão de experiências de vida nas narrativas de Dona Geni, pois para Benjamin (1979), é por meio desse elemento que o narrador aconselha o ouvinte.

A orientação para o interesse prático é um traço característico de muitos narradores natos. [...] Tudo aponta para a relação que isso mantém com qualquer narrativa verdadeira. Clara ou oculta, ela carrega consigo sua utilidade. Esta pode consistir ora numa lição de moral, ora numa indicação prática, ora num ditado ou norma de vida - em qualquer caso o narrador é um homem que dá conselhos ao ouvinte (BENJAMIN, 1979, p. 59).

Ademais, considerando o silenciamento de vozes consolidado pela historiografia oficial que, ao mesmo tempo em que beneficia o discurso dos vencedores em detrimento dos dominados, contribui com a barbárie que lega ao 


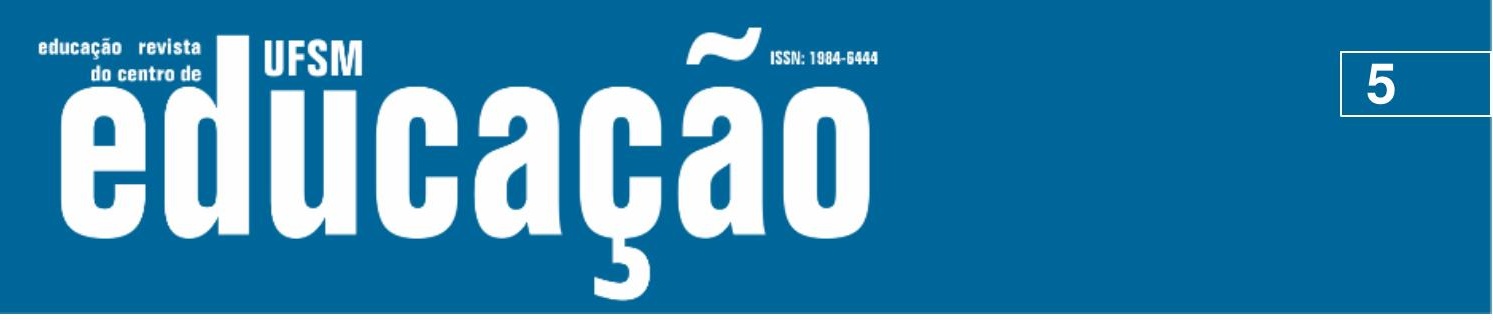

ISSN: 1984-6444 | http://dx.doi.org/10.5902/1984644435418

esquecimento o processo de transmissão dos bens culturais do povo, buscamos favorecer em nossa pesquisa a necessária tarefa de "[...] escovar a história a contrapelo" (BENJAMIN, 2012, p. 245), atentos à voz de sujeitos da educação transmissores de bens culturais deixados de lado pela historiografia hegemônica.

\section{Experiência de si, educação, cultura e memória}

Para Larrosa (1994, p. 43), a experiência de si é o que o sujeito oferece de si mesmo a seu próprio ser "[...] quando se observa, se decifra, se interpreta, se descreve, se julga, se narra, se domina, quando faz determinadas coisas consigo mesmo, etc.". A experiência de si também se configura como algo que deve ser transmitido, que deve ser aprendido. A cultura transmite, portanto, determinado "[...] repertório de modos de experiência de si, e todo novo membro de uma cultura deve aprender a ser pessoa em alguma das modalidades incluídas nesse repertório" (LARROSA, 1994, p. 45).

É como se a educação, desse modo, não apenas construísse e transmitisse uma experiência do mundo exterior, mas também construísse e transmitisse "[...] a experiência que as pessoas têm de si mesmas e dos outros como "sujeitos". Ou, em outras palavras, tanto o que é ser pessoa em geral como o que para cada uma é ser ela mesma em particular" (LARROSA, 1994, p. 45, grifo do autor).

E como, em grande parte, a experiência de si constitui-se a partir das narrações, aquilo que somos e, ainda, o sentido de quem somos depende das histórias que contamos para o outro e para nós mesmos. Essas histórias, por sua vez, se constroem em relação às narrativas que escutamos, que lemos, que experienciamos, e são "[...] produzidas e mediadas no interior de práticas sociais mais ou menos institucionalizadas" (LARROSA, 1994, p. 48).

Qualquer lugar em que se efetiva a constituição ou a transformação da experiência de si, qualquer lugar em que são aprendidas ou modificadas as relações estabelecidas pelo sujeito consigo mesmo é, para Larrosa (1994), um dispositivo pedagógico. As narrativas de Dona Geni, coletadas de experiências vividas ou relatadas, são rememoradas e tornadas novamente experiência do ouvinte no 


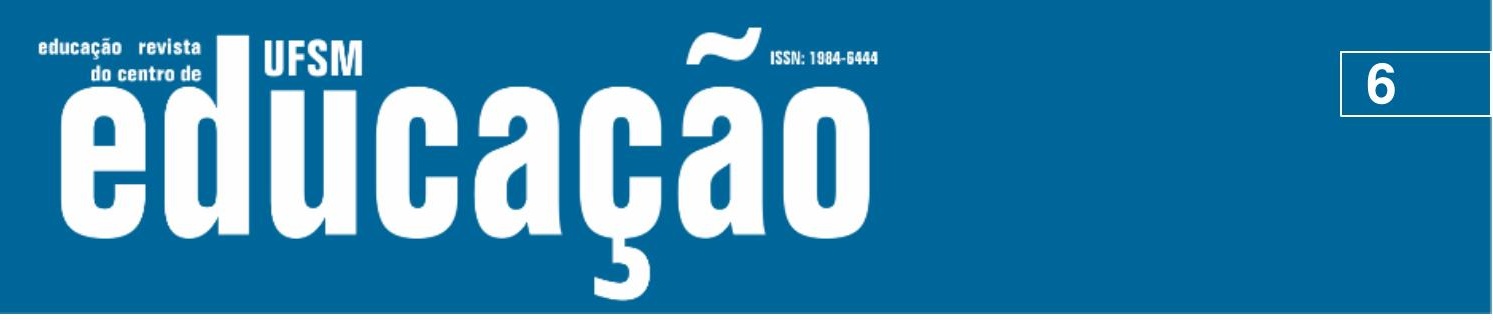

ISSN: 1984-6444 | http://dx.doi.org/10.5902/1984644435418

dispositivo pedagógico instituído no tempo e espaço da narração.

Segundo Girardello (2014, p. 22), é a memória quem guarda cenas de nossas vidas e as transforma em algo extremamente valioso que é o relato oral, a autora evidencia ainda que esses relatos transcendem a família e passam a ser elementos de significados e de riqueza simbólica de comunidades inteiras.

Larrosa (1994, p. 68) acrescenta que a recordação requer a habilidade narrativa de imaginar e de compor, de produzir sentido sobre o que somos. "O narrador é que expressa, no sentido de exteriorizar, o rastro que aquilo que viu deixou em sua memória”. No movimento de narrar, o contador de histórias numera e ordena os rastros que conservam aquilo que foi visto, escutado, lido. O tempo da história se constitui nessa ordenação.

Essa ampla rede de ordenações da memória e de produções de sentidos sobre si por meio das narrativas constitui e transmite a experiência de si em um processo educacional contínuo.

\section{Metodologia, locus, corpus, sujeito}

Um largo intervalo separa a coleta das narrativas por meio de entrevistas gravadas em 2002 e sua análise em 2015 e 2016. O coautor deste artigo, após retornar ao Espírito Santo em 1998 depois de haver residido por seis anos no Rio de Janeiro-RJ, detectou um processo acelerado de rarefação de narradores tradicionais nas comunidades camponesas do Espírito Santo em decorrência, dentre outros fatores, do acelerado processo de globalização propagado pela mídia televisiva com a expansão da rede elétrica e do alcance dos sinais de TV (na época, por meio do uso de parabólicas) no campo.

Suas primeiras entrevistas, sempre realizadas no interior, se deram nos anos de 1999 e 2001 nos municípios de Castelo-ES e Venda Nova do Imigrante-ES (região serrana do estado), onde residiu na ocasião. As visitas eram feitas a partir da busca, entre moradores das comunidades, dos nomes de narradores tradicionais da região. Após consentimento dos sujeitos, a entrevista era feita com uso de gravador de fita cassete, papel e prancheta. Em alguns casos fazia-se uso apenas de papel e 


\section{Aillbapẫ \\ 3}

ISSN: 1984-6444 | http://dx.doi.org/10.5902/1984644435418

despejo de lama no Rio Doce. Tivemos, em 09 de agosto de 2016, nove meses após a tragédia, a oportunidade de visitar Povoação. Na ocasião, a entrevistada havia falecido recentemente e a vila de pescadores, outrora graciosa e vívida, parecia anestesiada. A filha de Dona Geni recebeu-nos em sua casa simples onde residia com seu filho, neto de Dona Geni. Ela relatou as dificuldades, decorrentes da tragédia, por que passavam a sua família e outros tantos moradores do local, sobretudo pela impossibilidade de realização da atividade econômica que thes deu sustento por décadas: a pesca. Relatou ainda a situação de escassez e as dificuldades vividas em decorrência do derramamento de lama somadas à dificuldade de deslocamento para a cidade.

Cabe ressaltar que Povoação fica a 40 quilômetros do Centro de Linhares e seu acesso se dá pela rodovia ES-248 (considerando que 30 quilômetros da via não são pavimentados e que na ocasião esse trecho apresentava estado precário de manutenção). O tempo de deslocamento por ônibus é de cerca de $1 \mathrm{~h} 40 \mathrm{~min}$ pela linha "Linhares x Povoação" da viação Unimar, única que atende a região, com quatro horários diários de partida de segunda-feira a sábado e dois horários nos domingos e feriados.

Também era perceptível no semblante das pessoas que encontramos na vila a sensação de impotência e desânimo diante do trágico acontecimento, diante da morte de um rio de suma importância para o Brasil, para o Sudeste, para o Espírito Santo, para a vida de cada um dos sujeitos que mora às suas margens e que vivia de seus frutos.

Tais fatos tornam ainda mais relevantes os dados apresentados e o material coletado por meio desta pesquisa como registro e memória da comunidade para seu processo de re-existência na conjuntura atual e para futuros projetos que possibilitem a transmissão da experiência de si das narrativas de Dona Geni às novas gerações. 


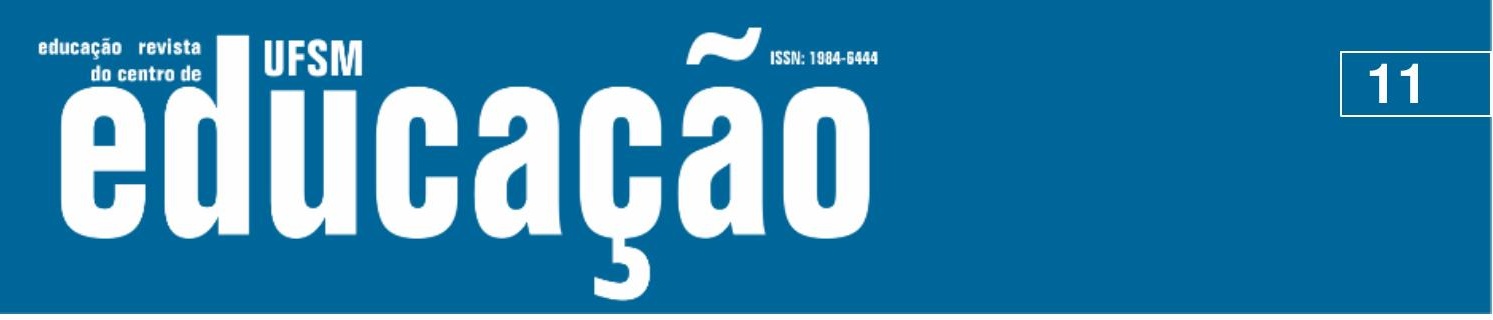

ISSN: 1984-6444 | http://dx.doi.org/10.5902/1984644435418

\section{As narrativas de Dona Geni: da fala para a escrita}

Para uma melhor compreensão da abrangência do corpus do trabalho, apresentamos uma breve análise descritiva dos áudios coletados. Nas transcrições (DELGADO, 2006) todas as falas que não foram de Dona Geni foram identificadas com a palavra entre parênteses indicando "pesquisador", "neto" e "filho". Também apresentamos em todos os áudios da entrevista, sua duração em minutos (min) e segundos (s), bem como a contagem de caracteres com espaços das transcrições feitas.

No primeiro áudio (20s), encontramos a apresentação feita pelo pesquisador, onde são registrados a data, o local da gravação e o nome completo da entrevistada, e é anunciado que ela a seguir irá nos contar um tanto da tradição e da sabedoria do povo. A transcrição do áudio alcançou 189 caracteres com espaços.

No segundo áudio (1min47s), encontramos relatos de memórias da vida de Dona Geni. A transcrição desse áudio chegou a 1.323 caracteres com espaços: "[...] naquele tempo era assim uma roça, um atraso, né? [...] Eu estudei pouco. Não tinha condições. Meu pai não tinha condições de botar nós para estudar porque não tinha mesmo, né? Não tinha estrada. Aqui tinha o Juparanã" (Dona Geni), embarcação a vapor que a partir de 1927 realizou transporte de pessoas e mercadorias no Rio Doce. Segundo Dona Geni, seu pai "[...] era um pobre coitado" (Dona Geni). Para estudar, as pessoas andavam pela matinha até chegar a uma casa onde funcionava o colégio.

No terceiro áudio (2min47s), com 2.059 caracteres com espaços em sua transcrição, o pesquisador pergunta se as pessoas mais velhas contavam muitas histórias para ela, e que tipo de histórias. Nesse momento, Dona Geni rememora histórias contadas para ela e para suas irmãs, principalmente na época da quaresma, como a história do Boitatá, e acrescenta:

Meu pai era muito instrutivo, conversava com nós dentro de casa. [...] Todo mundo sentado em volta dando atenção, né... Lamparina acesa. [...] Ele não gostava que nós, assim, saísse pra rua, eu então fui muito bem acionada, eu só dormia depois que eu fazia um metro de renda, ele tinha prazer de eu tá ali trocando bilro ali [...] era meu serviço, né? (Dona Geni). 


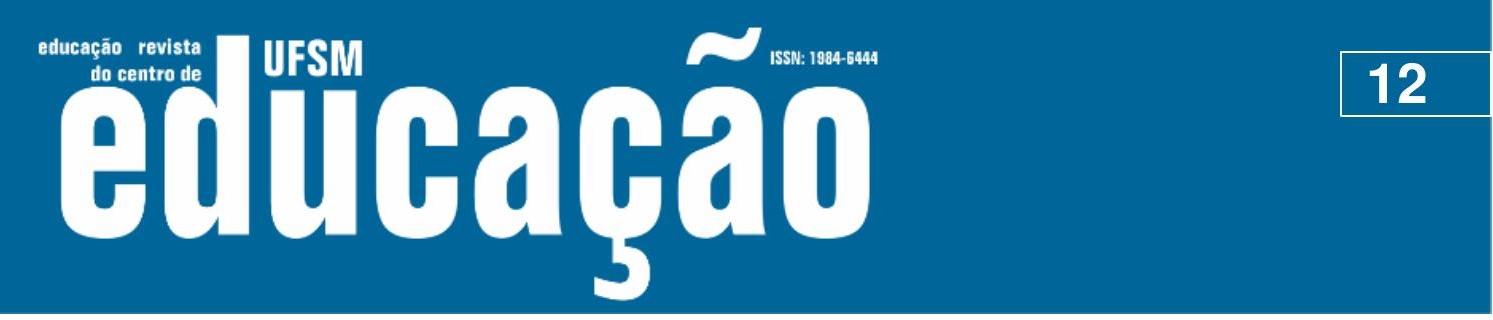

ISSN: 1984-6444 | http://dx.doi.org/10.5902/1984644435418

No quarto áudio (40s), com 359 caracteres com espaços em sua transcrição, Dona Geni conta um pouco sobre o trabalho do pai, jangadeiro de Regência a Colatina, que contava muitas histórias dessas travessias. Ele, por medo de seguir viagem à noite, encalhava a embarcação para prosseguir durante o dia.

No quinto áudio (1min34s), com transcrição em 1.287 caracteres com espaços, Dona Geni narra um episódio sobre o Caboclo-d’Água, ser mitológico classificado por Cascudo (1983, p. 127; 1998, p. 209) entre os Ipupiaras que vivem nas águas, frequentemente presente em relatos dos moradores das comunidades que margeiam o Rio São Francisco.

Então ele [seu pai] falava assim: - Cê não vai tomar banho no rio que aqui tem Caboclo d'água. Ele falava. Aí quando foi um dia, foi eu mais minhas irmãs, chegou lá, nós vimos mesmo, quase que pegou nós (risos). [...] Ele [0 Caboclo] correu atrás de nós e nós corremo gritando. Ele [seu pai] disse: mas eu disse a vocês que tinha e vocês não me obedeceram (Dona Geni).

No sexto áudio (40s), o pesquisador pergunta a Dona Geni sobre a Mãed'Água, mito pesquisado e descrito por Cascudo (1983, p. 131; 1998, p. 532), também familiar aos Ipupiaras, ao Boto e à Cobra Grande. Ela responde que nunca a viu, mas que seu pai "[...] contava que via" (Dona Geni). O relato foi transcrito em 321 caracteres com espaços.

A transcrição do sétimo áudio (2min2s) alcançou 1.413 caracteres com espaços. Não conseguimos compreender todas as palavras, pois alguns trechos foram ditos em intensidade baixa. No áudio, Dona Geni fala sobre o Saci-Pererê, ser mitológico presente em relatos do Brasil interior, sobretudo das regiões Sul e Sudeste (1983, p. 99; 1998, p. 794). Seu filho Prudêncio participou da conversa.

Nós tinha um rapaz que morava com nós aqui. [...] Aí, né, ele inventou de sair de noite lá pra uma fazenda que tem ali pra cima do Império, do Zé Rangel [...] Aí eu falei assim: - Olha, meu pai dizia que passou de seis horas tem que haver respeito. Não pode andar de noite que disse que tem 0 Saci - Ele disse: - Ah, tem Saci nada, eu vou - Ele disse que ia e foi. Quando ele chegou ali [...] aí ele se assombrou e veio embora, chegou aqui bateu na porta [...] veio o, o bicho, atrás dele assoviando: Siiiiiit, Saci Pererê. Falou mesmo, eu ouvi. Aí ele bateu: - Oh, dona Geni, me acode eu estou assombrado, bem que a senhora me falou - ele disse assim. - Eu tô vendo, eu escutei né, mas maior são os poder de Deus! Nós não devemos de abusar. O senhor foi abusado (Dona Geni). 


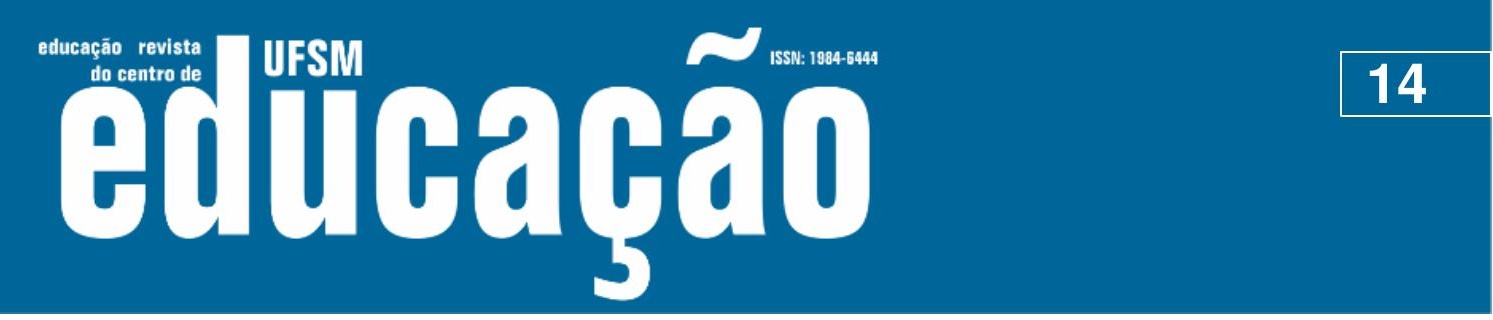

ISSN: 1984-6444 | http://dx.doi.org/10.5902/1984644435418

famoso naufrágio ocorrido em Regência.

Bom, eu ouvi falar assim que Regência, como... até hoje, eles ainda... eles ainda louvam ele [...] Caboclo Bernardo, né? É que salvou muita gente, né? Não foi no meu tempo [...] Tem até a avenida lá, Caboclo Bernardo, né? Eles fazem a festa lá, né? foi muito, como..., assim, come... comemorativa, né? Ficou na história essa história do Caboclo Bernardo (Dona Geni).

No décimo terceiro áudio ( $3 \mathrm{~min} 20 \mathrm{~s}$ ), transcrito em 1.321 caracteres com espaços, e no décimo quarto (2min1s), com transcrição em 1.363 caracteres com espaços, Dona Geni aborda algumas questões sobre a educação.

[...] aqui em casa dá muita criança, sabe? [...] mas a gente tem um modo de tratar as crianças. Então, um dia desses, tava ali, essa pracinha tava cheia de crianças, mas cheia, eles tavam até brigando ali, sabe? Aí então eu cheguei e falei assim: - Meus filho, não briga não, briga de criança chega pra papai e mamãe, vocês são umas criança, umas criança bonita, vem aqui, vem cá pra nós, pra nós contar um bocado de história.

Primeiro o carinho sai de nós da casa e depois o da escola, porque se nós não souber agradar as nossas crianças, como é que ele vai chegar na escola? [...] quando eles tão aqui comigo assim eu sempre, é eu ensino assim modos deles tratar uma pessoa, né? Eu ensino, né? Bom dia, boa tarde, bença, né? Eu ensino assim, né? Eu aprendi muito pouco. Naquela época não tinha escola. [...] Eu não tenho coragem de chamar uma professora pelo nome. Eu chamo Dona. (Dona Geni).

O décimo quinto áudio (1min45s) inicia-se com o pesquisador indagando sobre algum fato importante que tenha marcado a sua vida. Dona Geni afirma: "Porque importante nosso é nós ter amizade e o amor [...] Eu não sei o que eles [as pessoas que chegaram a Povoação] acharam comigo que eles se adapta muito assim comigo, sabe? É, sei não" (Dona Geni). A transcrição do áudio alcançou 1.179 caracteres com espaços.

Nos dois últimos áudios, décimo sexto (1min12s), transcrito em 809 caracteres com espaços e décimo sétimo (1 $1 \mathrm{min3s}$ ) transcrito em 1.090 caracteres com espaços, o pesquisador, Dona Geni e seu filho Prudêncio conversaram sobre o Rio Doce. Ela relatou: "O menino foi tomar o banho no rio. O menino pequeno, acho que tinha uns três anos e desapareceu que até hoje nunca ninguém viu, nunca ninguém soube" (Dona Geni). Ela e seu filho contaram que muitas pessoas já haviam sido levadas pelo rio: "Muita gente. Muita gente" (Dona Geni). Seu filho finaliza afirmando: "Todo mundo que é de Povoação sabe nadar no rio [...] todos nós 


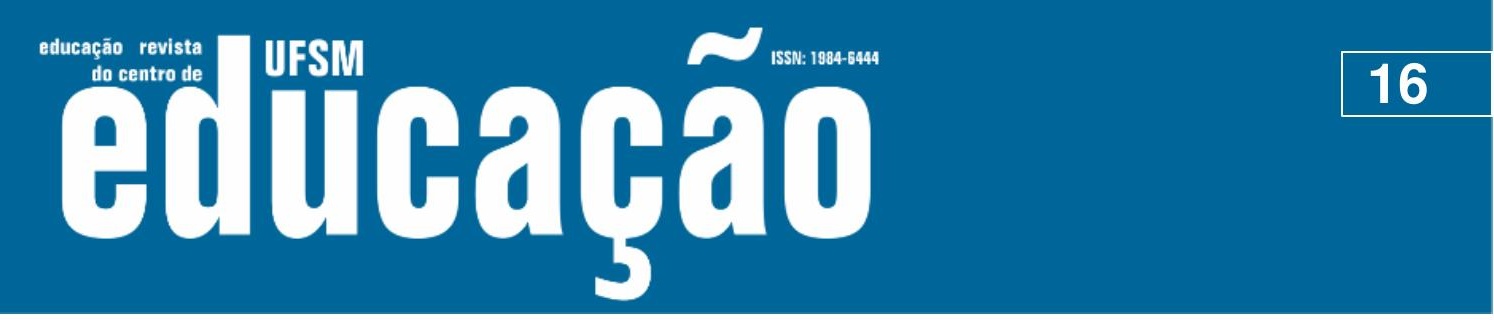

ISSN: 1984-6444 | http://dx.doi.org/10.5902/1984644435418

quando eu subi a barreira, que eu cheguei em casa, passou aquele fogaréu assim por mim, aquela peneira, aí eu caí. Era o Boi tatá. Eu vi [...] Aí papai falou. Papai ainda achou ruim com ela [sua mãe] que ela fez aquilo." (Dona Geni).

Também pudemos notar que em diferentes momentos as narrativas de Dona Geni de Oliveira Ramos atestam a instituição de dispositivos pedagógicos e práticas educacionais. Em alguns trechos, a narradora se refere às crianças a quem educava e contava as suas histórias:

[...] aqui em casa dá muita criança. sabe? Aqui, graças a Deus, essa casa aqui não falta criança. Então, mas a gente tem um modo de tratar as crianças. Então, um dia desses, tava ali, essa pracinha tava cheia de crianças, mas cheia, eles tavam até brigando ali, sabe? Aí então eu cheguei e falei assim: - Meus filho, não briga não, briga de criança chega pra papai e mamãe, vocês são umas criança, umas criança bonita, vem aqui, vem cá pra nós, pra nós contar um bocado de história. [...]

Primeiro o carinho sai de nós da casa e depois o da escola, porque se nós não souber agradar nossas crianças como é que ele vai chegar na escola? Não é? Então, sai de nós pra depois ir da escola não é? Aí eles ficam. Graças a Deus eles ficaram tudo assim instrutivo assim comigo. [...] É quando eles tão aqui comigo assim eu sempre, é eu ensino assim modos deles tratar uma pessoa, né? Eu ensino, né? Bom dia, boa tarde, bença, né? Eu ensino assim, né? (Dona Geni).

Em outros trechos, ela se refere ao modo como seu pai as educava, também por meio das histórias:

[...] meu pai era muito instrutivo, conversava com nós dentro de casa [...] É, ele contava que ele era jangadeiro lá em Regência, de Regência a Colatina, sabe? Ele trabalhava na jangada carregando tora de Colatina até Regência nesse Rio Doce, né? Então ele contava muita histórias [...] (Dona Geni).

Outros trechos de seus relatos nos permitem inferir que do mesmo modo como ela fora educada por seu pai, ela também educou seus filhos, as crianças da comunidade e as pessoas que com ela conviveram. Além de dizer que seu pai contava histórias e era instrutivo, Dona Geni relata o modo com seu pai ressaltava os conselhos nos momentos oportunos, como na ocasião em que apesar dele haver recomendado que ela e suas irmãs não saíssem para tomar banho de rio, elas saíram e lá encontraram os Caboclos-d'Água. Seu pai, num processo educacional familiar, Ihes disse: "[...] mas eu disse a vocês que tinha e vocês não me obedeceram" (Dona Geni). Esse processo educacional deflagrado por seu pai se 


\section{Tilusm Aillathá}

ISSN: 1984-6444 | http://dx.doi.org/10.5902/1984644435418

E o que nossa narradora nos teria a dizer sobre o seu saber? Ou sobre o seu processo educacional de transmissão da experiência de si e de transformação da consciência de si? Ou ainda sobre sua participação nesse gigantesco conjunto de narrativas que é a cultura?

Dona Geni, que reunia as crianças em sua casa ou na pracinha (localizada a poucos metros de sua casa), mesmo após narrar várias memórias de sua vida, envolvendo as pessoas de sua família e de sua comunidade, em meio ao ambiente e ao contexto histórico e social do local onde viveu, afirma em princípio que não sabia muito para poder ensinar, mas logo em seguida reconhece que aprendeu e ensinou o que para ela era o mais importante:

"Eu aprendi pouco. Naquela época não tinha escola" (Dona Geni).

O pesquisador retruca: "A senhora que pensa que aprendeu pouco, viu?" (Pesquisador).

Ela concorda: “É (risos). Agora... coisa importante, respeito, né?” (Dona Geni).

O pesquisador responde, concordando: "É" (Pesquisador).

E Dona Geni conclui: "Eu não tenho coragem de chamar uma professora pelo nome. Eu chamo Dona ${ }^{3}$. Porque ela tem, né? Ela tem o importante dela qual eu não tenho. Chamo todo mundo Dona Fulana" (Dona Geni).

\section{Era uma vez, na margem norte da foz do Rio Doce...}

Por fim, o Rio Doce.

Na ocasião da entrevista, esse mesmo Rio Doce que já levou "Muita gente. Muita gente". (Dona Geni) e que impõe respeito de tal modo que todos os moradores de Povoação sabem nadar no rio (como nos foi informado na entrevista), de um lado tirava algumas vidas, mas de outro dava vida a todos os moradores da singela vila de Povoação. Geni e seu filho concentraram-se no relato de algumas vidas que se perderam no grande rio. Quanto à vida dada pelo rio, isso não precisava ser contado. Era parte da vida, como o ar que se respira, algo que simplesmente impregnava as narrativas, enchia os pratos de peixe, molhava os rostos, fazia brotar sorrisos e fecundar mitos. O rio era, e pensava-se que seria sempre, a um só tempo 


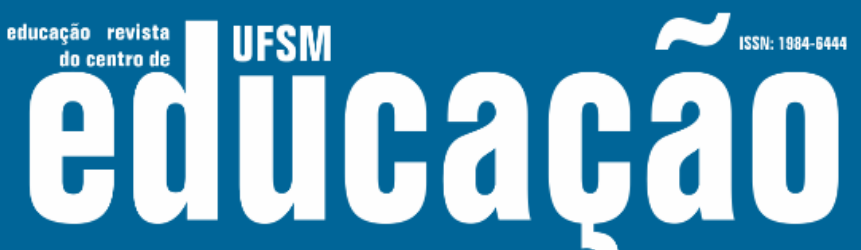

ISSN: 1984-6444 | http://dx.doi.org/10.5902/1984644435418

e em todos os tempos, meio de sustento e via de transporte dos moradores de suas margens, piscina, brinquedo e fonte de criações imaginárias, dispositivos pedagógicos e práticas educacionais de inúmeras gerações de crianças ribeirinhas.

Ao regressarmos a Povoação, Dona Geni havia acabado de partir dessa vida, quase junto com o rio. Ela partira poucos meses após uma tragédia impensável, inimaginável nos tempos em que seu pai singrava a correnteza do Rio Doce com sua jangada, nos tempos em que o vapor Juparanã era o único meio de transporte coletivo do local, nos tempos em que os Caboclinhos e o Boitatá habitavam seu leito, nos tempos em que a vida, toda vida de seu entorno, existia em função do Rio Doce, rio vida. Mas o rio, que outrora abrigou narrativas, modos de viver, meios de vida, experiências de si, processos educacionais e dispositivos pedagógicos singulares, afogou-se em lama. Lamentável morte de um rio. Como lamentável também foi para nós saber da partida de Dona Geni em um momento em que a comunidade tanto precisava de suas narrativas, de sua experiência de si, de seus conselhos e ensinamentos.

Consideramos que a pesquisa alcançou seus objetivos, no entanto, algo um tanto amargo nos assombrou no curso de sua realização. Pensamos que há muito mais o que fazer com o que ora temos em mãos. Como as águas retornam filtradas por meio da chuva ao Rio Doce num pranto que aos poucos tenta lavar o que o homem sujou, para quiçá refazerem o que um dia a ganância fez destruir, iniciamos os contatos com a comunidade com o intuito de fazermos o caminho inverso, entregando à vila de Povoação retextualizações das narrativas de Dona Geni, que poderão ser lidas por crianças e adultos da comunidade em seu processo reexistência para que as memórias do Rio Doce e de Povoação, presentes na experiência de si de suas histórias, fomentem produções de sentidos e constituições de sujeitos que criem, transmitam e narrem, junto a outras experiências de si e dispositivos pedagógicos presentes na comunidade, uma nova história na dura luta por um recomeço, por um renascer. Tomara que seja Doce $!^{4}$. 


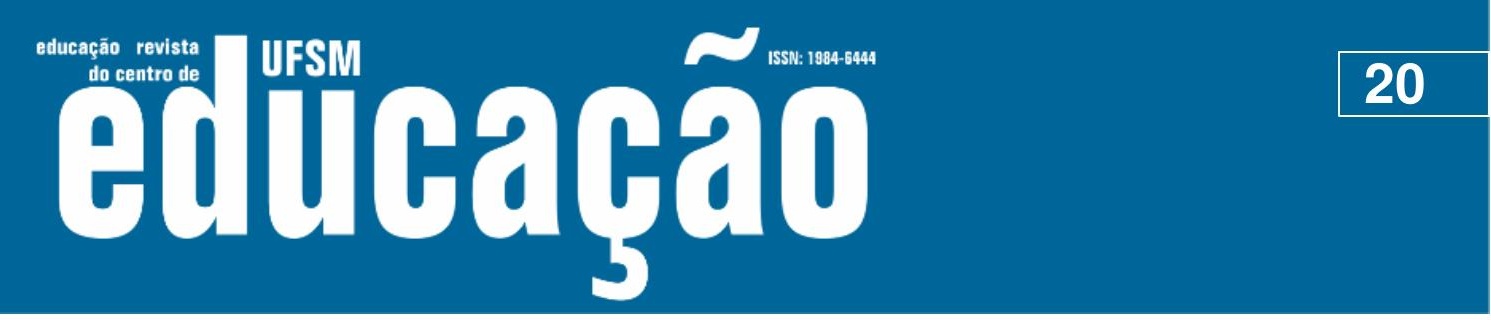

ISSN: 1984-6444 | http://dx.doi.org/10.5902/1984644435418

\section{Referências}

BENJAMIN, Walter. O Narrador. In: Textos escolhidos. Tradução de Modesto Carone. 2.ed. São Paulo: Abril Cultural, 1979, p. 57-74.

BENJAMIN, Walter. Sobre o conceito da história. In: Magia e técnica, arte e política: ensaios sobre literatura e história da cultura. Tradução de Sérgio Paulo Rouanet. 3. ed. São Paulo: Brasiliense, 2012. p. 241-252.

CASCUDO, Luís da Câmara. Geografia dos mitos brasileiros. Belo Horizonte: Itatiaia; São Paulo: EdUSP, 1983.

CASCUDO, Luís da Câmara. Dicionário do folclore brasileiro. 3. ed. Rio de Janeiro: Ediouro, 1998.

DELGADO, Lucília de Almeida Neves. História Oral: memória, tempo, identidades. Belo Horizonte: Autêntica, 2006.

GIRARDELLO, Gilka. Uma clareira no bosque: Contar histórias na escola. Campinas: Papirus, 2014.

LARROSA, Jorge. Tecnologias do eu e educação. In: Silva, Tomaz Tadeu (Org.). 0 sujeito da educação. Tradução de Tomaz Tadeu da Silva. Petrópolis: Vozes, 1994, p.35-86.

LARROSA, Jorge. Linguagem e educação depois de Babel. Tradução: Cynthia Farina. Belo Horizonte: Autêntica, 2004.

MARCUSCHI, Luiz Antônio. Da fala para a escrita: atividades de retextualização. 8. ed. São Paulo: Cortez, 2007.

MELLO, Thiago. Antemanhã. Correio da Manhã: $1^{\circ}$ Caderno. Rio de Janeiro, n. 19436, p. 9, 4 ago. 1956.

SILVEIRA, Denise Tolfo; CÓRDOVA, Fernanda Peixoto. A pesquisa científica. In: GERHARDT, Tatiana Engel; SILVEIRA, Denise Tolfo (Orgs.). Métodos de pesquisa. Porto Alegre: Editora da UFRGS, 2009, p. 31-42.

\section{Correspondência}

Fabiano Oliveira Moraes - Universidade Federal do Espírito Santo - Av. Fernando Ferrari, 514, Goiabeiras, CEP 29075-910, Vitória, Espírito Santo, Brasil. 


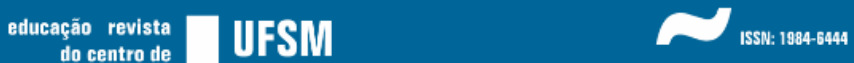

ISSN: 1984-6444 | http://dx.doi.org/10.5902/1984644435418

\section{(c) $(1) \otimes$}

This work is licensed under a Creative Commons Attribution-NonCommercial 4.0 International (CC BY-NC 4.0)

\section{Notas}

\footnotetext{
1 Pesquisa financiada pelo CNPq por meio de bolsa de Iniciação Científica concedida à coautora.

2 Obtivemos autorização prévia para identificação do sujeito pesquisado e para publicação de seus textos.

3 Em respeito à valorização do uso de "Dona" pela entrevistada ao se referir às professoras e considerando-a uma narradora que instituía processos educacionais e dispositivos pedagógicos no tempo e espaço da narração, optamos por identificá-la, neste trabalho, sempre como "Dona" Geni.

4 Alusão ao Rio Doce e ao trecho "Tomara que seja azul!", do poema "Antemanhã", de Thiago de Mello: "O mundo está começando / agora, na tua mão. / Tudo pode acontecer! / Cuidado!, de tua palma, / aberta sob as estrelas, / o mundo está começando / a se erguer: como se fosse / um pássaro que se acorda, / que acabou de se acordar, / e vai sair para um vôo / - porque tem fome de céu. / (Tomara que seja azul!) [...]" (MELLO, 1956, p. 9).
} 